\title{
Propostas para a organização prática das ações de saúde bucal na unidade básica de saúde da família. Uma revisão de literatura
}

\author{
Practical organization proposals for the oral health \\ actions in the family public health care center. A literature review
}

Lívia Fernanda Sabadin

Cirurgiã dentista da UBSF Di Napoli, Município de Cerquilho, São Paulo, Brasil.

Carolina Simonetti Lodi

Professora do curso de Especialização em Saúde da Família UNASUS-UNIFESP, São Paulo, Brasil e Professora das Faculdades Integradas de Santa Fé do Sul, São Paulo, Brasil.

\section{RESUMO}

Este artigo tem como objetivo propor, por meio de revisão bibliográfica, melhorias para a organização das ações de saúde bucal na Unidade de Saúde da Família sem excluir a legitimidade do contexto histórico já existente. A metodologia utilizada foi o levantamento bibliográfico da temática proposta publicada no período de 2005 a 2011. Foram pesquisados artigos de periódicos nacionais e documentos do Ministério da Saúde. Os resultados mostraram que há necessidade de melhorar a organização das ações na Unidade de Saúde da Família. As ações necessitam incluir todas as perspectivas do processo saúde-doença, dando respostas de promoção e proteção à saúde. As conquistas dependem de formas comprometidas de compreensão do processo de trabalho em saúde e da adoção de um modelo com matriz na integralidade para transformar o complexo mundo de necessidades da saúde bucal.

Palavras chave: PROGRAMA SAÚDE DA FAMÍLIA; SAÚdE BUCAL; ATENÇÃO PRIMÁRIA À SAÚdE; EDUCAÇÃO EM SAÚDE BUCAL; RECURSOS HUMANOS EM ODONTOLOGIA.

\footnotetext{
ABSTRACT

This literature review aimed at proposing strategies to improve the organization of oral health practices in the Family public health care center without excluding the legitimacy of the existing historical context. The methodology used was based on a literature review of works published exclusively in the Portuguese language from 2005 to 2011. The authors searched for national periodicals and documents issued by the Health Division. The main aspects involving the organization of actions at the Family public health care center were assessed. Future actions should include all perspectives of the health-disease process, providing solutions to promote and protect health. The achievements depend on the committed comprehension of the work process in health and the adoption of a model based on the integrity to transform the complex world of needs in oral health.

Keywords: FAMILY HEALTH PROGRAM; ORAL HEALTH; PRIMARY HEALTH CARE; EDUCATION ON ORAL HEALTH; DENTAL STAFF.
} 
PROPOSTAS PARA A ORGANIZAÇÃO PRÁtICA DAS AÇÕES DE SAÚdE BUCAL NA UNIDADE BÁSICA DE SAÚDE DA FAMÍLIA. UMA REVISÃO DE LITERATURA

\section{INTRODUÇÃO}

Em março de 1994, o Ministério da Saúde criou o Programa de Saúde da Família (PSF), hoje definido como Estratégia Saúde da Família (ESF), com o objetivo de reordenar as práticas de saúde no âmbito da atenção básica em novas bases e critérios, reafirmando e incorporando os princípios básicos do Sistema Único de Saúde (SUS) de universalização, descentralização, integralidade e participação da comunidade. ${ }^{1}$

De acordo com o documento oficial que define as bases do programa, a Estratégia Saúde da Família pauta suas ações priorizando a proteção e promoção à saúde dos indivíduos, das famílias e das comunidades de forma integral e contínua ${ }^{2}$

Em relação aos recursos humanos operantes, as equipes eram compostas apenas por médico e enfermeiro. Em 1997, foram incorporados o auxiliar de enfermagem e quatro a seis agentes comunitários de saúde. Neste momento inicial, a saúde bucal não teve seus profissionais incluídos na equipe mínima, apesar de existir, àquela época, um movimento nacional em prol da inclusão da equipe de odontologia no Programa de Saúde da Família ${ }^{3}$

A incorporação oficial das equipes de saúde bucal (ESB) na ESF ocorreu em dezembro de 2000, com a publicação da Portaria MS $1.444 / 2000^{4}$, no qual o Ministério da Saúde determinou o incentivo financeiro às ESB na ESF. A necessidade de ampliação do acesso da população brasileira às ações de promoção, prevenção e recuperação da saúde bucal, a necessidade de melhorar os índices epidemiológicos da saúde bucal e a necessidade de incentivar a reorganização da saúde bucal na atenção básica foram os motivadores da implantação das ações da saúde bucal na ESF. O cirurgião-dentista, o auxiliar de consultório dentário e o técnico de higiene dental foram incluídos na equipe. ${ }^{2-3}$
A organização das ações e dos serviços de saúde cria a possibilidade de compreender a realidade e os principais problemas e necessidades da população. Essa estratégia permite o atendimento ao usuário nas Unidades Básicas de Saúde, atividades realizadas para a população de suas respectivas áreas de abrangência, uma ação gerencial mais efetiva, uma melhora no planejamento e o acompanhamento e a avaliação, conferindo às equipes de saúde qualidade diferenciada em seu processo de trabalho. Uma forma de organizar o trabalho em saúde é adotar o trabalho em equipe, em que os profissionais, de acordo com seus conhecimentos e com os recursos disponíveis, buscam a melhor solução que cada problema exige. ${ }^{5}$

Historicamente, as práticas de saúde bucal no setor saúde indicam que ela foi desenvolvida a distância, sendo feita praticamente entre quatro paredes, restrita à prática do cirurgião-dentista com seu equipamento odontológico. Atualmente, a incorporação das ações de saúde bucal pelas ESFs visa superar este modelo de organização e prática anterior, sendo altamente desafiador e difícil, na medida em que procura integrar a prática dos profissionais da equipe odontológica. ${ }^{5}$

O modelo de assistência da ESF constitui um desafio para o cirurgião-dentista que, como participante da equipe de saúde, deve levar em consideração o envolvimento de seus atos com os aspectos sociais, políticos, econômicos e culturais importantes para o processo de transição e consolidação do novo modelo de assistência à saúde. ${ }^{6}$ Nessa atenção à saúde bucal,

vislumbra-se uma possibilidade de aumento de cobertura, de efetividade na resposta às demandas da população e de alcance de medidas de caráter coletivo. As maiores possibilidades de ganhos situam-se nos campos do trabalho em equipe, das relações com os usuários e da gestão, 
implicando uma nova forma de produzir o cuidado em saúde bucal. ${ }^{7}$

$\mathrm{Na}$ prática da ESF, constatam-se múltiplas tensões na organização do trabalho. Apesar de as atividades com o coletivo, com as famílias, nas casas, locais de trabalho e convivência serem uma atribuição do conjunto da equipe, elas são assumidas principalmente pelos agentes comunitários de saúde (ACS), seguidos pelos profissionais da enfermagem. A demanda por assistência, por meio das consultas clínicas, é extremamente pesada e ocupa grande parte da agenda dos médicos e dentistas. $^{8}$

Em relação à prática de saúde bucal, observa-se uma supervalorização dos procedimentos em detrimento de ações voltadas para a integralidade da atenção. Sem novas tecnologias, o cuidado clínico fica restrito, ou reproduz, o modelo hegemônico, individual e curativista. Além disso, as equipes, em especial as de saúde bucal, enfrentam muitas dificuldades para lidar com a demanda espontânea, e a atenção a elas quase sempre se restringe ao esquema de queixa-conduta, queixa-procedimento. $^{8}$

Neste sentido, a perspectiva do presente trabalho é propor, por meio de revisão bibliográfica, melhorias para a organização das ações de saúde bucal na Unidade de Saúde da Família sem excluir a legitimidade do contexto histórico já existente.

\section{Metodologia}

O estudo apresenta revisão bibliográfica e análise documental e suas reflexões e discussões foram construídas com base nas bibliografias específicas sobre a saúde bucal na Estratégia Saúde da Família. O critério de inclusão dos artigos constituiu em estudos na íntegra disponíveis nas bases de dados pesquisadas que tratavam sobre o tema de pesquisa. Os critérios de exclusão foram: indisponibilidade do texto na íntegra nas bases de dados, textos publicados fora do período determinado para o estudo ou estar escrito em inglês. Os trabalhos publicados em inglês foram excluídos do estudo, pois a opção de se utilizar apenas trabalhos publicados em língua portuguesa visou facilitar o acesso dos profissionais vinculados às Unidades Básicas de Saúde da Família, além de valorizar a literatura científica nacional.

Para alcançar o objetivo proposto, o estudo percorreu algumas etapas como: levantamento bibliográfico, partindo das palavras-chave apresentadas; análise do material pré-selecionado, leitura seletiva para definir o material de real interesse ao trabalho e leitura crítica buscando definições conceituais por meio de análise e compreensão dos conceitos. Procedeu-se à leitura cuidadosa dos resumos das referências bibliográficas encontradas para posterior seleção das que tratavam especificamente de estudos referentes à saúde bucal na ESF.

As bases de dados utilizadas foram as do sistema Lilacs-Scielo do portal Biblioteca Virtual em Saúde (Bireme), portal da Revista de Atenção Primária à Saúde e consulta de textos do Caderno de Atenção Básica do Ministério da Saúde. A busca foi realizada no período de julho a agosto de 2012, e os textos selecionados foram aqueles publicados no período de 2006 a 2011.

Os termos utilizados no levantamento bibliográfico foram: programa saúde da família, saúde bucal, atenção primária à saúde, educação em saúde bucal e equipe saúde bucal.

Após excluir os artigos que não se enquadravam nos critérios do estudo, procedeu-se à leitura cuidadosa dos resumos dos trabalhos encontrados para, posteriormente, realizar a leitura na íntegra dos trabalhos e a seleção daqueles que tratavam especificamente de estudos referentes à saúde bucal na ESF. Diante disso, foram selecionados 
23 artigos do banco de dados online, e após leitura e avaliação na íntegra dos trabalhos, apenas dez tratavam especificamente de estudos referentes à saúde bucal na ESF e por isso foram utilizados na elaboração deste artigo, além de dois documentos do Ministério da Saúde. O material bibliográfico, após ter sido submetido a leitura criteriosa, foi comparado e avaliado quanto ao seu contributo para o objetivo do estudo.

\section{Resultados}

Por meio do presente estudo, foi possível analisar os principais aspectos que envolvem a organização das ações de saúde bucal na Unidade de Saúde da Família. Os dados encontrados nos trabalhos selecionados estão descritos na Tabela 1.

TABELA 1 - Artigos sobre as ações de saúde bucal na Unidade de Saúde da Família selecionados para o presente estudo.

\begin{tabular}{|c|c|c|c|}
\hline $\begin{array}{c}\text { Título do } \\
\text { Artigo }\end{array}$ & Autores/Ano & Resultados & Conclusões \\
\hline $\begin{array}{l}\text { 1. Papel do } \\
\text { cirurgião } \\
\text { dentista na } \\
\text { equipe de } \\
\text { saúde da } \\
\text { família. }\end{array}$ & $\begin{array}{c}\text { Farias MR, } \\
\text { Sampaio JJC. } \\
(2011)^{3}\end{array}$ & $\begin{array}{l}\text { Demonstrou através da literatura atual } \\
\text { como sistematizar a participação do ci- } \\
\text { rurgião dentista no processo de trabalho } \\
\text { da equipe de saúde da família, observou- } \\
\text {-se como ocorre a interdisciplinaridade, } \\
\text { destacando características, facilidades e } \\
\text { dificuldades. }\end{array}$ & $\begin{array}{l}\text { Conclui-se que a saúde bucal } \\
\text { está inserida no Programa } \\
\text { Saúde da Família ainda de } \\
\text { forma incipiente, desenvolvendo } \\
\text { uma prática autônoma, curativa } \\
\text { e sem interação com os demais } \\
\text { saberes e sujeitos da equipe. }\end{array}$ \\
\hline $\begin{array}{l}\text { 2. Processo } \\
\text { de trabalho } \\
\text { na Estratégia } \\
\text { de Saúde da } \\
\text { Família: uma } \\
\text { perspectiva a } \\
\text { partir da equipe } \\
\text { de saúde } \\
\text { bucal. }\end{array}$ & $\begin{array}{l}\text { Cruz DB, Gabardo } \\
\text { MCL, Ditterich } \\
\text { RG, Moysés SJ, } \\
\text { Nascimento AC. } \\
(2009)^{2}\end{array}$ & $\begin{array}{c}\text { A análise indicou uma importante } \\
\text { participação da ESB nos Conselhos } \\
\text { Locais de Saúde, da ordem de } 78,7 \% \text {. A } \\
\text { maioria dos cirurgiões-dentistas }(79,3 \%) \\
\text { avaliou que os cidadãos usuários dos } \\
\text { serviços locais têm acesso dificultado às } \\
\text { especialidades. }\end{array}$ & $\begin{array}{c}\text { Conclui-se que há evidências } \\
\text { de que as ESB incorporaram as } \\
\text { bases conceituais e a forma de } \\
\text { atuar de maneira coerente com } \\
\text { os princípios da ESF e do SUS, } \\
\text { entretanto há necessidade de } \\
\text { investimentos em uma maior } \\
\text { capacitação das equipes em } \\
\text { temas específicos. }\end{array}$ \\
\hline $\begin{array}{l}\text { 3. Saúde bucal } \\
\text { no Programa } \\
\text { Saúde da } \\
\text { Família: uma } \\
\text { avaliação } \\
\text { do modelo } \\
\text { assistencial. }\end{array}$ & $\begin{array}{c}\text { Souza TMS, } \\
\text { Roncalli AG. (2007) } \\
{ }_{11}\end{array}$ & $\begin{array}{l}\text { O trabalho identificou precariedade } \\
\text { nas relações de trabalho e dificuldades } \\
\text { no referenciamento para média e alta } \\
\text { complexidade, na intersetorialidade, no } \\
\text { diagnóstico epidemiológico e na avaliação } \\
\text { das ações. A maioria dos municípios } \\
\text { apresentou pouco ou nenhum avanço no } \\
\text { modelo assistencial em saúde bucal. Os } \\
\text { municípios que demonstraram avanços } \\
\text { apresentaram alta expectativa de vida ao } \\
\text { nascerem, baixas taxas de mortalidade } \\
\text { infantil, valores per capita entre os mais } \\
\text { altos do Estado e altos valores de IDH-M. }\end{array}$ & $\begin{array}{l}\text { Concluiu-se que políticas } \\
\text { públicas que contemplam } \\
\text { aspectos além dos pertinentes } \\
\text { ao setor saúde são decisivas } \\
\text { para uma real mudança nos } \\
\text { modelos assistenciais. }\end{array}$ \\
\hline
\end{tabular}

FOL • Faculdade de Odontologia de Lins/Unimep • 23(1) 26-36 • jan.-jun. 2013 


\begin{tabular}{|c|c|c|c|}
\hline $\begin{array}{l}\text { 4. Processo de } \\
\text { trabalho em } \\
\text { saúde bucal: } \\
\text { em busca de } \\
\text { diferentes } \\
\text { olhares para } \\
\text { compreender e } \\
\text { transformar a } \\
\text { realidade. }\end{array}$ & $\begin{array}{l}\text { Faccin D, Sebold } \\
\text { R, Carcereri DL. } \\
\quad(2010)^{9}\end{array}$ & $\begin{array}{l}\text { Verificou-se que com a implementação } \\
\text { de novas diretrizes para a ESB sem } \\
\text { a definição clara de suas implicações } \\
\text { operacionais, e considerando-se ainda as } \\
\text { dificuldades locais, a prática odontológica } \\
\text { recebeu nova denominação, mas se } \\
\text { manteve praticamente inalterada. }\end{array}$ & $\begin{array}{l}\text { O estudo contribuiu no sentido } \\
\text { de propor caminhos para } \\
\text { incorporar ao processo de } \\
\text { trabalho em saúde bucal os } \\
\text { avanços conceituais da ESF. O } \\
\text { processo de trabalho na ESF } \\
\text { mostra-se como um importante } \\
\text { tema para pesquisas futuras, } \\
\text { assim como a abordagem mais } \\
\text { aprofundada do processo de } \\
\text { trabalho da ESB na ESF. }\end{array}$ \\
\hline $\begin{array}{l}\text { 5. Organização } \\
\text { das ações em } \\
\text { saúde bucal } \\
\text { na Estratégia } \\
\text { de Saúde da } \\
\text { Família: ações } \\
\text { individuais } \\
\text { e coletivas } \\
\text { baseadas em } \\
\text { dispositivos } \\
\text { relacionais e } \\
\text { instituístes. }\end{array}$ & Santos AM. (2006) ${ }^{8}$ & $\begin{array}{l}\text { Verificou-se que existe um grande número } \\
\text { de estudos que apontam sugestões para } \\
\text { as ações em saúde bucal, mas a grande } \\
\text { maioria apoia-se, preferencialmente, no } \\
\text { levantamento epidemiológico como eixo } \\
\text { orientador das práticas. Neste sentido } \\
\text { apontaram-se direções e propostas como: } \\
\text { organização dos serviços centrado no } \\
\text { usuário, acolhimento e organização da } \\
\text { demanda, que fossem desencadeadas } \\
\text { por dispositivos instituístes, relacionais e } \\
\text { integradores na organização do processo } \\
\text { de trabalho da ESB nas suas ações } \\
\text { individuais e coletivas. }\end{array}$ & $\begin{array}{l}\text { A organização das ações } \\
\text { dos serviços em saúde bucal } \\
\text { necessita de algumas ações } \\
\text { intersetoriais que viabilizem } \\
\text { em curto prazo, mudanças } \\
\text { consideráveis no processo } \\
\text { de organização da saúde } \\
\text { bucal. No entanto, tais } \\
\text { conquistas dependem de } \\
\text { formas comprometidas de } \\
\text { compreensão do processo de } \\
\text { trabalho em saúde e da adoção } \\
\text { de um modelo com matriz na } \\
\text { integralidade para transformar } \\
\text { o complexo mundo de } \\
\text { necessidades em saúde bucal. }\end{array}$ \\
\hline $\begin{array}{l}\text { 6. O } \\
\text { acolhimento } \\
\text { como } \\
\text { ferramenta } \\
\text { de práticas } \\
\text { inclusivas de } \\
\text { saúde. }\end{array}$ & $\begin{array}{c}\text { Silva LG, Alves MS. } \\
(2008)^{10}\end{array}$ & $\begin{array}{l}\text { Através de levantamento bibliográfico } \\
\text { obteve-se o acolhimento como uma } \\
\text { estratégia para: reorganização do serviço } \\
\text { de saúde, mudança do foco de trabalho } \\
\text { da doença para o doente, destaque na } \\
\text { importância do trabalho de uma equipe } \\
\text { multiprofissional, garantia do acesso } \\
\text { universal aos serviços de saúde, alcance } \\
\text { de resolutividade dos problemas ou } \\
\text { necessidades de saúde, promoção da } \\
\text { humanização na assistência e estímulo } \\
\text { à capacitação dos profissionais, fazendo } \\
\text { com que estes assumam uma postura } \\
\text { acolhedora. A relação do trabalhador com } \\
\text { o usuário, o estabelecimento de vínculos, } \\
\text { a credibilidade e a confiança entre eles } \\
\text { são, aparentemente, consequências do } \\
\text { acolhimento. }\end{array}$ & $\begin{array}{c}\text { Com o estudo, conclui-se } \\
\text { que a assistência de saúde } \\
\text { humanizada e com qualidade } \\
\text { é responsabilidade de toda } \\
\text { a equipe multiprofissional e } \\
\text { garantida pelo acolhimento } \\
\text { como resultado de práticas de } \\
\text { saúde a serem executadas } \\
\text { antes, durante e após o } \\
\text { atendimento. }\end{array}$ \\
\hline
\end{tabular}


PROPOSTAS PARA A ORGANIZAÇÃO PRÁTICA DAS AÇÕES DE SAÚDE BUCAL NA UNIDADE BÁSICA DE SAÚDE DA FAMÍLIA. UMA REVISÃO DE LITERATURA

\begin{tabular}{|c|c|c|c|}
\hline $\begin{array}{l}\text { 7. Atenção } \\
\text { e cuidado } \\
\text { em saúde } \\
\text { no ambiente } \\
\text { familiar: } \\
\text { aspectos } \\
\text { da visita } \\
\text { domiciliar. }\end{array}$ & $\underset{12}{\text { Abrahão AL. (2011) }}$ & $\begin{array}{c}\text { A visita domiciliar ocorre por meio da ESF } \\
\text { em muitos municípios, sendo utilizada } \\
\text { como uma das formas de organização } \\
\text { da atenção em saúde realizada pela } \\
\text { equipe multiprofissional. A equipe elabora } \\
\text { estratégias de ação a serem desenvolvidas } \\
\text { junto à família. }\end{array}$ & $\begin{array}{c}\text { Conclui-se que a visita domiciliar } \\
\text { permite maior integração entre } \\
\text { as ações que acontecem no } \\
\text { domicílio e as que ocorrem } \\
\text { no interior dos serviços de } \\
\text { saúde, sendo fundamental para } \\
\text { a construção de um sistema } \\
\text { de saúde único, integral e } \\
\text { equânime. }\end{array}$ \\
\hline $\begin{array}{l}\text { 8. A prática } \\
\text { da enfermeira } \\
\text { no Programa } \\
\text { de Saúde da } \\
\text { Família: a } \\
\text { interface da } \\
\text { vigilância da } \\
\text { saúde versus } \\
\text { as ações } \\
\text { programáticas } \\
\text { em saúde. }\end{array}$ & $\begin{array}{l}\text { Nascimento MS, } \\
\text { Nascimento MAA. } \\
(2005)^{1}\end{array}$ & $\begin{array}{l}\text { Os resultados evidenciaram que a ESF } \\
\text { é uma estratégia de (re)orientação do } \\
\text { Modelo de Atenção à Saúde e um caminho } \\
\text { para consolidação do SUS. As práticas } \\
\text { das enfermeiras da ESF são assistenciais, } \\
\text { gerenciais e educativas. }\end{array}$ & $\begin{array}{c}\text { Pode-se concluir que a } \\
\text { execução da organização do } \\
\text { trabalho em saúde, com práticas } \\
\text { articuladas de promoção, } \\
\text { prevenção de doenças e } \\
\text { agravos, recuperação e } \\
\text { reabilitação da saúde de grupos } \\
\text { populacionais e intervenções } \\
\text { sobre a família, tem resultado } \\
\text { na reestruturação da atenção } \\
\text { básica e na reorganização do } \\
\text { sistema local de saúde. }\end{array}$ \\
\hline $\begin{array}{l}\text { 9. Adequação } \\
\text { de recursos } \\
\text { humanos } \\
\text { ao PSF: } \\
\text { percepção de } \\
\text { formandos de } \\
\text { dois modelos } \\
\text { de formação } \\
\text { acadêmica em } \\
\text { odontologia. }\end{array}$ & $\begin{array}{l}\text { Sanchez HF, } \\
\text { Drumond MM, } \\
\text { Vilaça EL. } \\
\qquad(2008)^{5}\end{array}$ & $\begin{array}{l}\text { Nesse estudo, ficou demonstrado que } \\
\text { a convivência com cenários sociais } \\
\text { chocantes causa nos estudantes um } \\
\text { impacto que pode superar o aprendizado } \\
\text { pelas vias tradicionais, aí incluídas a } \\
\text { família, a religião e principalmente a } \\
\text { formação acadêmica clássica. } \\
\text { Esse achado parece demonstrar } \\
\text { que incorporar o dado "realidade" à } \\
\text { experiência acadêmica leva à formação } \\
\text { de profissionais que respondem mais } \\
\text { satisfatoriamente às necessidades da } \\
\text { população. }\end{array}$ & $\begin{array}{l}\text { Os resultados colhidos no } \\
\text { presente estudo indicam que } \\
\text { as dificuldades relacionadas } \\
\text { ao mercado de trabalho } \\
\text { podem estar sendo decisivas } \\
\text { junto aos acadêmicos: existe } \\
\text { grande desejo pelo trabalho em } \\
\text { uma equipe do PSF, em uma } \\
\text { demonstração de esgotamento } \\
\text { do caráter liberal da profissão. }\end{array}$ \\
\hline $\begin{array}{l}\text { 10. Práticas } \\
\text { das equipes de } \\
\text { saúde bucal } \\
\text { na Estratégia } \\
\text { Saúde da } \\
\text { Família e a } \\
\text { construção } \\
\text { (Des) } \\
\text { construção da } \\
\text { integralidade } \\
\text { em Feira de } \\
\text { Santana-BA. }\end{array}$ & $\begin{array}{l}\text { Rodrigues AAAO, } \\
\text { Fonseca GS, } \\
\text { Siqueira DVS, Assis } \\
\text { MMA, Nascimento } \\
\text { MAA. }(2010)^{7}\end{array}$ & $\begin{array}{c}\text { Impasses foram identificados e foi notável } \\
\text { constatar que há muitos desafios a serem } \\
\text { vencidos para que as Equipes de Saúde } \\
\text { Bucal trabalhem em conformidade com os } \\
\text { princípios da integralidade. }\end{array}$ & $\begin{array}{l}\text { A responsabilização através de } \\
\text { ações de promoção que tem } \\
\text { por objetivo a melhoria das } \\
\text { condições de saúde bucal e } \\
\text { geral da comunidade assistida } \\
\text { acontece de forma heterogênea } \\
\text { nas USF por grande parte } \\
\text { dos profissionais. Mas ainda } \\
\text { é necessário incentivar a } \\
\text { capacitação dos profissionais, } \\
\text { que atuam no PSF de Feira de } \\
\text { Santana, sensibilizando-os para } \\
\text { importância de desenvolver } \\
\text { uma prática baseada na } \\
\text { integralidade. }\end{array}$ \\
\hline
\end{tabular}


Algumas estratégias de melhorias para o serviço encontradas nos trabalhos selecionados foram agrupadas e estão descritas na Tabela 2.

\section{Dıscussão}

Anecessidadedereorganizaçãodomodelo assistencial tradicional, centrado nas práticas curativas e de atenção individual, foi essencial para a implementação do SUS, em base local, a partir de 1990. Os princípios e diretrizes da universalidade, equidade, integralidade, controle social, descentralização, resolutividade e humanização orientam a operacionalização das ações e serviços, provocando avanços na qualidade do atendimento e buscando garantir a toda a população acesso aos serviços de saúde de qualidade. ${ }^{2}$

O cumprimento dos princípios do SUS, como a universalidade e equidade, requer das equipes de saúde bucal o conhecimento de sua realidade local, de sua comunidade adstrita. O modelo de assistência do ESF constitui um desafio para o cirurgião-dentista que, como participante da equipe de saúde, deve levar em consideração o envolvimento de seus atos com os aspectos sociais, políticos, econômicos e culturais importantes para o processo de transição e consolidação do novo modelo de assistência à saúde. Daí a necessidade de organizar as ações valendo-se de estratégias de programação que utilizem critérios para a priorização da população mais necessitada. Quando os serviços conseguirem apropriar-se dessa tecnologia e compartilhar suas prioridades com a comunidade, todos se beneficiarão, pondo-se em prática dois princípios do SUS: a equidade e o controle social ${ }^{6-12}$.

Segundo Santos, ${ }^{9}$ o primeiro passo para a organização das ações e dos serviços em saúde bucal seria a ampliação e adoção do critério de uma ESF para cada ESB, o que não acontece em muitos municípios, garantindo serviços básicos de saúde bucal em todas as unidades de saúde, incluindo áreas rurais de difícil acesso. Posteriormente, a inclusão de novos trabalhadores de saúde, como o técnico de saúde bucal, ampliaria a resolubilidade das ações, propiciando ao cirurgião-dentista mais tempo para dedicar-se a atividades mais complexas. $^{9}$

Para que haja organização das ações em saúde bucal, devem-se incluir todas as perspectivas do processo saúde-doença, ou seja, dar respostas de promoção e proteção à saúde, ações de recuperação e reabilitação. No entanto, necessitará estar articulada a uma rede de serviços hierarquizada, possibilitando a resolutividade das diferentes demandas apresentadas pelos usuários. Paralelamente, não poderá ser construída sem a participação dos diferentes sujeitos trabalhadores da saúde (médicos, enfermeiros, técnicos e auxiliares de enfermagem, cirurgiõesdentistas, técnicos e auxiliares de saúde bucal, agentes comunitários de saúde, entre outros), bem como só terá legitimidade se houver a compreensão e participação da comunidade, e do usuário individual no momento da busca por um serviço de saúde bucal. ${ }^{9}$

Adefinição de metas-a quantidade e o tipo de atividades a serem realizados - não propõe a normatização em práticas programáticas; pelo contrário, parte do pressuposto da necessidade de uma ação planejada e programada. A organização dos serviços de saúde envolve o atendimento ao usuário nas Unidades Básicas de Saúde da Família e outras atividades realizadas para a população de suas respectivas áreas de abrangência. ${ }^{5}$

Com a inserção das ESB nas ESF apontou-se uma mudança no processo de trabalho. O trabalho em equipe multiprofissional leva à integralidade da atenção pelas ações que valorizam o acolhimento, o vínculo com a população a as ações continuadas de saúde. ${ }^{10}$

Um dos principais problemas enfrentados no cotidiano dos serviços de saúde bucal 
TABELA 2. Estratégias de melhorias para os serviços prestados na Estratégia Saúde da Família.

\begin{tabular}{|c|c|}
\hline Estratégias de melhorias para o serviço & $\begin{array}{l}\text { Referências } \\
\text { citadas }\end{array}$ \\
\hline $\begin{array}{l}\text { Como participante da equipe de saúde, o cirurgião dentista deve levar em consideração o } \\
\text { envolvimento de seus atos com os aspectos sociais, políticos, econômicos e culturais importantes } \\
\text { para o processo de transição e consolidação do novo modelo de assistência à saúde. }\end{array}$ & $5,7,8,9,10,11$ \\
\hline Priorização da população mais necessitada para garantir equidade e o controle social. & $5,7,8,9,10,11$ \\
\hline $\begin{array}{l}\text { Inclusão de novos trabalhadores de saúde como o técnico de saúde bucal, ampliando a } \\
\text { resolubilidade das ações, propiciando ao cirurgião dentista mais tempo para dedicar-se a atividades } \\
\text { mais complexas. }\end{array}$ & 8 \\
\hline $\begin{array}{l}\text { Para que haja a organização das ações em saúde bucal devem-se incluir todas as perspectivas } \\
\text { do processo saúde-doença, ou seja, dar respostas de promoção e proteção à saúde, ações de } \\
\text { recuperação e reabilitação. }\end{array}$ & 8 \\
\hline $\begin{array}{l}\text { Os serviços de saúde bucal devem ser organizados de forma a acolher a demanda espontânea e os } \\
\text { casos de urgência, e dar respostas às necessidades sentidas pela população. }\end{array}$ & 5,7 \\
\hline $\begin{array}{l}\text { As ações de saúde bucal devem estar integradas às demais ações de saúde da unidade e os } \\
\text { profissionais capacitados para atuar de forma multiprofissional e interdisciplinar. }\end{array}$ & 5,7 \\
\hline $\begin{array}{l}\text { O acolhimento pode contribuir para a ampliação do acesso aos serviços de saúde e para a } \\
\text { adequação do processo de trabalho em direção a respostas satisfatórias às necessidades da } \\
\text { população. }\end{array}$ & 3,10 \\
\hline $\begin{array}{l}\text { Cada Unidade de Saúde precisará reorganizar suas estruturas físicas, ou seja, a infraestrutura } \\
\text { também deve ser entendida como elemento constituinte do cuidado. }\end{array}$ & 8 \\
\hline $\begin{array}{l}\text { As ESB deverão criar cartazes informativos sobre os cuidados em saúde bucal e disponibilizar na } \\
\text { recepção os horários de atendimento, os serviços realizados, o número de vagas disponibilizadas } \\
\text { diariamente e os critérios de agendamento, tudo isso, de forma clara e acessível. }\end{array}$ & 8 \\
\hline $\begin{array}{l}\text { As ESB devem juntamente com as ESF conhecer os dados de suas respectivas áreas de } \\
\text { abrangência (população por faixa etária, condições de saneamento, doenças, entre outros) para } \\
\text { definir formas de inserção dos diferentes grupos de forma equitativa e ética. }\end{array}$ & 8 \\
\hline $\begin{array}{l}\text { O agendamento deverá ser por hora marcada com ofertas de atendimento em dois turnos, não } \\
\text { esquecendo que todos os casos devem ser acolhidos, incluindo as urgências. }\end{array}$ & $5,7,8$ \\
\hline $\begin{array}{l}\text { As ações da ESB vão muito além de procedimentos restauradores e reabilitadores. As ações devem } \\
\text { também ser de promoção e proteção em saúde bucal podendo ser chamadas de ações coletivas. }\end{array}$ & 8 \\
\hline
\end{tabular}

é a organização da demanda, em especial nas atividades assistências, o que deve ser amplamente discutido entre usuários e trabalhadores de saúde. As equipes, em especial as de saúde bucal, enfrentam muitas dificuldades para lidar com a demanda espontânea, e a atenção a elas quase sempre se conforma ao esquema queixa-conduta, queixa-procedimento. De acordo com o Ministério da Saúde, ${ }^{5}$ compreende-se como universo de atenção à saúde bucal, toda a população da área de abrangência da Unidade Básica de Saúde da Família. Os serviços de saúde bucal devem ser organizados de forma a acolher a demanda espontânea e os casos de urgência e dar respostas às necessidades sentidas pela população, sendo um importante caminho para resolutividade da atenção, o que contribui para a legitimidade da equipe na comunidade em que está inserida. As 
ações de saúde bucal devem estar integradas às demais ações de saúde da unidade e os profissionais capacitados para atuar de forma multiprofissional e interdisciplinar. ${ }^{5-8}$

Para superar o acesso descontextualizado na organização da demanda e das necessidades dos diferentes grupos populacionais, concorda-se com as Diretrizes das políticas de saúde bucal quando aponta duas formas de inserção: 1) por linha de cuidado; e (2) por condição de vida. A primeira prevê o reconhecimento de especificidades próprias da idade, podendo ser trabalhada com a saúde da criança, saúde do adolescente, saúde do adulto e saúde do idoso. Já a proposta de atenção à condição de vida, compreende a saúde da mulher, saúde do trabalhador portador de necessidades especiais, hipertensos, diabéticos, dentre outros. $^{7-9}$

O acolhimento pode contribuir para a ampliação do acesso aos serviços de saúde e para a adequação do processo de trabalho em direção a respostas satisfatórias às necessidades da população. É preciso estabelecer vínculo com o usuário, acolhendo-o com a qualidade de saber quando ouvir e quando calar. Além disso, ele é uma estratégia para a reorganização dos serviços de saúde, para a mudança do foco de trabalho da doença para o doente, destaque na importância do trabalho de uma equipe multiprofissional, garantia do acesso universal aos serviços de saúde, promoção da humanização na assistência e estímulo à capacitação dos profissionais, fazendo com que estes assumam uma postura acolhedora. $3,5,11$

O planejamento das ações de saúde bucal deve ser feito em conjunto com a equipe de saúde, principalmente em relação às ações propostas por ciclo de vida, condição de vida ou por fatores de risco comuns a várias doenças. As ações devem visar ao fortalecimento dos indivíduos e das comunidades no processo de definição de prioridade, tomada de decisões, planejamento e implantação de estratégias que levem à obtenção de saúde. ${ }^{5}$

De acordo com Nascimento e Nascimento, ${ }^{1}$ o modelo de organização do processo de trabalho das ESF é pautado nas ações programáticas em saúde, com práticas predominantemente voltadas à assistência. No entanto, podemos extrair alguns componentes da vigilância à saúde, como acolhimento, sala de espera, sistema de informação, atividades extramuros, reuniões da comunidade e planejamento. $^{6}$

Cada Unidade de Saúde precisará reorganizar suas estruturas físicas. As recepções deverão ser amplas, com assentos adequados e suficientes, possuir aparelhos audiovisuais (televisão, som ambiente, vídeos educativos etc.), pintura agradável, arquivos informativos, ou seja, a infraestrutura também deve ser entendida como elemento constituinte do cuidado. As ESBs deverão criar cartazes informativos sobre os cuidados em saúde bucal e disponibilizar na recepção os horários de atendimento, os serviços realizados, o número de vagas disponibilizadas diariamente e os critérios de agendamento; tudo isso de forma clara e acessível. Deverão possuir área adequada para atividades educativas e pré-consulta, onde se podem desenvolver salas temáticas, escovação supervisionada, entre outra atividades. Essas atividades poderão ser desempenhadas pelos diferentes trabalhadores da unidade, potencializando a interdisciplinaridade e a corresponsabilização dos demais membros da ESF com o processo de adoecimento relacionado à boca. ${ }^{9}$

As ESB devem, juntamente com as ESFs, conhecer os dados de suas respectivas áreas de abrangência (população por faixa etária, condições de saneamento, doenças, entre outros) para definir formas de inserção dos diferentes grupos de forma equitativa e ética. Não há sobreposição entre essas 
inserções e os critérios para a marcação de consultas, pois ambos podem complementarse e servir para justificativas acerca do acesso de um ou outro grupo. ${ }^{9}$

A marcação de consultas gera adota vários critérios em diferentes Unidades de Saúde e ainda é um dos maiores problemas encontrados, dificultando o acesso ao serviço odontológico. No entanto, caberá a cada Unidade de Saúde definir uma alternativa para a marcação de consultas, considerando que elas dependem do número de ESFs e ESBs em cada uma delas.

Quando possível, o agendamento deverá ser por hora marcada, com ofertas de atendimento em dois turnos, não esquecendo que todos os casos devem ser acolhidos, incluindo as urgências. O tempo de permanência dos usuários na Unidade de Saúde também deverá ser levado em consideração. A construção da agenda deve estar pautada nas necessidades da população a partir dos critérios epidemiológicos das áreas de abrangência e/ou de influência das Unidades de Saúde de forma equânime e universal, devendo ser amplamente discutida com a comunidade, nos conselhos de saúde em nível local e municipal. .,9 $^{5}$

O atendimento no ambiente familiar vem se constituindo como um dos focos das políticas de saúde no Brasil, com o potencial de tornar-se uma modalidade substitutiva dentro das práticas em saúde. Na ESF, a atenção no domicílio propiciada pela equipe de saúde insere o profissional no seio familiar, identificando demandas e potencialidades da família. A visita domiciliar é um procedimento rotineiro, realizado mensal e preferencialmente pelos ACSs. A ampliação e qualificação das ações de saúde bucal também se fazem pela organização de visitas da equipe de saúde bucal às pessoas acamadas ou com dificuldade de locomoção, visando à identificação dos riscos e propiciando o acompanhamento e tratamento necessários. Cada localidade deve planejar a melhor estratégia para que as visitas domiciliares aconteçam em suas comunidades. $^{9,13}$

As ações da ESB vão muito além de procedimentos restauradores e reabilitadores. As ações devem também ser de promoção e proteção em saúde bucal, podendo ser chamadas de ações coletivas. As ações coletivas são aquelas desenvolvidas com o intuito de atingir o maior número de pessoas pela promoção e proteção da saúde em diferentes espaços sociais (escolas, creches, associações, unidades de saúde, entre outras), ou seja, confere um caráter não formal ao processo de ensino/aprendizagem em saúde. ${ }^{9}$

A educação em saúde bucal deve fornecer instrumentos, respeitando a cultura local, tornando os sujeitos coletivos capazes de autogerirem seus processos de saúdedoença, sua vida, com vistas à melhoria da sua qualidade de vida. As ações educativas coletivas devem abordar: 1) as principais doenças bucais, como se manifestam e como se previnem; 2) a importância do autocuidado, da higiene bucal, da escovação com dentifrício fluoretado e o uso do fio dental; 3) os cuidados a serem realizados para evitar a fluorose; 4) orientações gerais sobre dieta; 5) a orientação para autoexame da boca; 6) cuidados após traumas dentais; 7) prevenção à exposição ao sol sem proteção; e 8) prevenção ao uso do álcool e fumo. ${ }^{5}$

\section{Conclusões}

O construir ou reconstruir da prática odontológica na ESF é um desafio que envolve não só os trabalhadores de saúde, mas também a política de saúde e as sociedades adscritas em cada território. Muitos são os obstáculos que dificultam a organização e o trabalho em equipe entre a ESF e a ESB. Assim, fica nítida a importância do estudo atual que traz sugestões para a organização das ações do processo de trabalho da ESB em uma tentativa de ampliar o 
acesso da população aos serviços e diminuindo as desigualdades em saúde bucal.

Com esse estudo foi possível apontar proposições para a organização das ações dos serviços de saúde sem excluir a legitimidade construída historicamente no seu arcabouço técnico-científico, bem como sugerir algumas ações intersetoriais que viabilizem, no curto prazo, mudanças consideráveis.

Embora ainda seja difícil mensurar o impacto das ações de saúde bucal na ESF, há um evidente progresso do ponto de vista da universalidade, equidade e integralidade na lógica desse trabalho.

\section{REFERÊNCIAS BIBLIOGRÁFICAS}

1. Nascimento MS, Nascimento MAA. A prática da enfermeira no Programa de Saúde da Família: a interface da vigilância da saúde versus as ações programáticas em saúde. Ciência \& Saúde Coletiva. 2005; 10(2): 333-45.

2. Cruz DB, Gabardo MCL, Ditterich RG, Moyses SJ, Nascimento AC. Processo de trabalho na Estratégia de Saúde da Família: uma perspectiva a partir da equipe de saúde bucal. Rev APS. 2009; 12(2): 168-75.

3. Farias MR, Sampaio JJC. Papel do cirurgião-dentista na equipe de saúde da família. Rev RGO. 2011; 59(1): 109-15.

4. Ministério da Saúde. Portaria n. ${ }^{\circ} 1.444$, de 28 de dezembro de 2.000 [acesso em 02 jun 2013]. Publicada no DOU de 29/12/00, seção 1, p. 85. Disponível em: http://www.mp.go.gov.br/portalweb/hp/2/docs/portaria1444_28_12_00.pdf

5. Ministério da Saúde. Cadernos de atenção básica. Saúde bucal. Brasília: Ministério da Saúde; 2008 [acesso em 28 ago 2012]. Disponível em: bvsms.saude.gov.br/bvs/publicacoes/saude_bucal.pdf

6. Sanchez HF, Drumond MM, Vilaça EL. Adequação de recursos humanos ao PSF: percepção de formandos de dois modelos de formação acadêmica em odontologia. Ciência \& Saúde Coletiva. 2008; 13(2): 523-31.

7. Ministério da Saúde. Diretrizes da política nacional de saúde bucal (p. 16). Brasília (DF): Ministério da Saúde; 2004 [acesso em 02 set 2012]. Disponível em: conselho.saude.gov.br/ web_comissoes/cisb/.../politica_nacional.pdf

8. Rodrigues AAAO, Fonseca GS, Siqueira DVS, Assis MMA, Nascimento MAA. Práticas das equipes de saúde bucal na Estratégia Saúde da Família e a construção (des)construção da integralidade em Feira de Santana-BA. Rev APS. 2010; 13(4): 476-85.

9. Santos AM. Organização das ações em saúde bucal na Estratégia de Saúde da Família: ações individuais e coletivas baseadas em dispositivos relacionais e instituístes. Rev APS. 2006; 9(2): 190-200.

10. Faccin D, Sebold R, Carcereri DL. Processo de trabalho em saúde bucal: em busca de diferentes olhares para compreender e transformar a realidade. Ciência \& Saúde Coletiva, 2010; 15(1): 1643-52.

11. Silva LV, Alves MS. O Acolhimento como ferramenta de práticas inclusivas de saúde. Rev APS. 2008; 11(1): 74-84.

12. Souza TMS, Roncalli AG. Saúde bucal no Programa Saúde da Família: uma avaliação do modelo assistencial. Caderno de Saúde Pública. 2007; 23(11): 2727-39.

13. Abrahão AL. Atenção e cuidado em saúde no ambiente familiar: aspectos da visita domiciliar. Rev APS. 2011; 14(4): 472-80.

\author{
Autora para contato \\ Carolina Simonetti Lodi \\ E-mail: carol_lodi@yahoo.com.br
}

Submetido em: 28-4-2013

Aceito em: 21-5-2013 